\title{
REFLEX THERAPY IN THE TREATMENT OF LOW BACK PAIN
}

\author{
Terzieva M., I. Dimitrov, B. Ivanov, N. Deleva, A. Kaprelyan, \\ D. Arabadzhieva, S. Geneva \\ Department of Neurology, Varna Medical University, \\ First Clinic of Neurology, "Sveta Marina" University Hospital, Varna
}

Reviewed by: assoc. prof. Sv. Kalevski

\section{SUMMARY}

Lumbar disc disease is a leading cause of low back pain. It represents a heavy burden for the patients and for the society, impairing working capacity and quality of life. Acute attacks of back pain are usually treated with a combination of analgesics, muscle relaxants and NSAIDs, but acupuncture is being applied increasingly as well. The aim of our study was to evaluate the effect of combined reflex therapy on low back pain. We assessed 34 patients with lumbar disc herniations and obtained positive results for the therapeutic effectiveness of combined treatment with acupuncture: quicker improvement of pain and muscle spasticity, lack of gastrointestinal adverse effects, faster recovery of the impaired working capacity.

Key words: acupuncture, disc herniation, low back pain, reflex therapy

\section{INTRODUCTION}

Epidemiological studies have shown that lumbar disc disease, one of the leading causes of low back pain, is most frequent during the third to fifth decade. This is the age when the burden of impaired working capacity is the heaviest for the patients and for the society. In this regard, the quick and effective treatment of one of the frequent causes of pain and impaired lumbosacral biomechanics, namely the lumbar disc herniation, with minimal adverse effects, is a matter of increasing importance.

Acute attacks of back pain are usually treated with a combination of analgesics, muscle relaxants and nonsteroidal anti-inflammatory drugs (NSAIDs) $(2,3)$. According to literature data, classical and laser acupuncture is applied increasingly as well. This is a therapeutical method used for analgesia, but also for trophic improvement. It is thought that the treatment induces a release of endorphins, more powerful than artificially synthesized ones. The correct selection of biological active points (BAP) and the application of combined treatment (classical and laser acupuncture, muscle relaxants) have a particular effect on the treatment outcome $(1,6,7)$.

\section{PURPOSE}

To assess the effect of combined reflex therapy on low back pain.

Address for correspondence:

I. Dimitrov, First Clinic of Neurology, "Sveta Marina" University Hospital, 1 Hr. Smirnenski str., 9010 Varna, Bulgaria

e-mail: indimitrov@mail.bg

\section{PATIENTS AND METHODS}

Thirty-four patients with CT-verified disc herniations, 28 men and 6 women, aged 23 to 52 years, were followed-up (Table 1).

Table 1. Distribution of patients according to age and sex

\begin{tabular}{||l|c|c||}
\hline \hline & Number & Age \\
\hline Men & 28 & $41,2 \pm 7,2$ \\
\hline Women & 6 & $39,0 \pm 7,0$ \\
\hline Total & 34 & $40,9 \pm 7,1$ \\
\hline \hline
\end{tabular}

Twenty-seven patients had a lateral disc herniation with relapsing lumbar pain and mono- or polyradicular ipsilateral symptoms (L4, L5 and/or S1), while 7 had a median disc herniation with alternating or bilateral radicular symptoms. Neurological examination revealed positive extension phenomena, dermatomal hypaesthesia, decreased or absent patellar or ankle reflexes. No motor weakness or bladder/bowel disturbances were found. Neuroimaging was performed, including CT and X-ray of the lumbar spine. Disc herniations were described at L3-L4 level in 8 cases, at L4- L5 in 14 cases, at L5- S1 in 12.

No surgical treatment was performed in any patient. Though it was recommended by a neurosurgeon in 9 cases, the patients refused the operation.

EMG demonstrated demyelination of different severity and location.

After a precise evaluation of indications, treatment was carried out in a hospital setting. All patients had history of pre- 
vious or current gastrointestinal complaints. Contrast X-ray and fibrogastroscopy revealed gastric or duodenal ulcers, acid reflux, and reflux esophagitis in 17 cases.

Reflex therapy was performed, up to 4 weeks from disease onset, using the classical technique of needle introduction in points with general influence, having a reflex action on the functional states of the central nervous system. Segmental points were used, spinal, from the paravertebral lines, predominantly from the bladder meridian (Fig.1): Sanjiaoshu, Shenshu, Quihaishu, Dachangshu, Guanyuanshu. Due to the dermatomal irradiation of pain, we also used points on the anterior, outer and/or posterior line of the leg: Huantiao, Yinmen, Chengfu, Kunlun, etc.

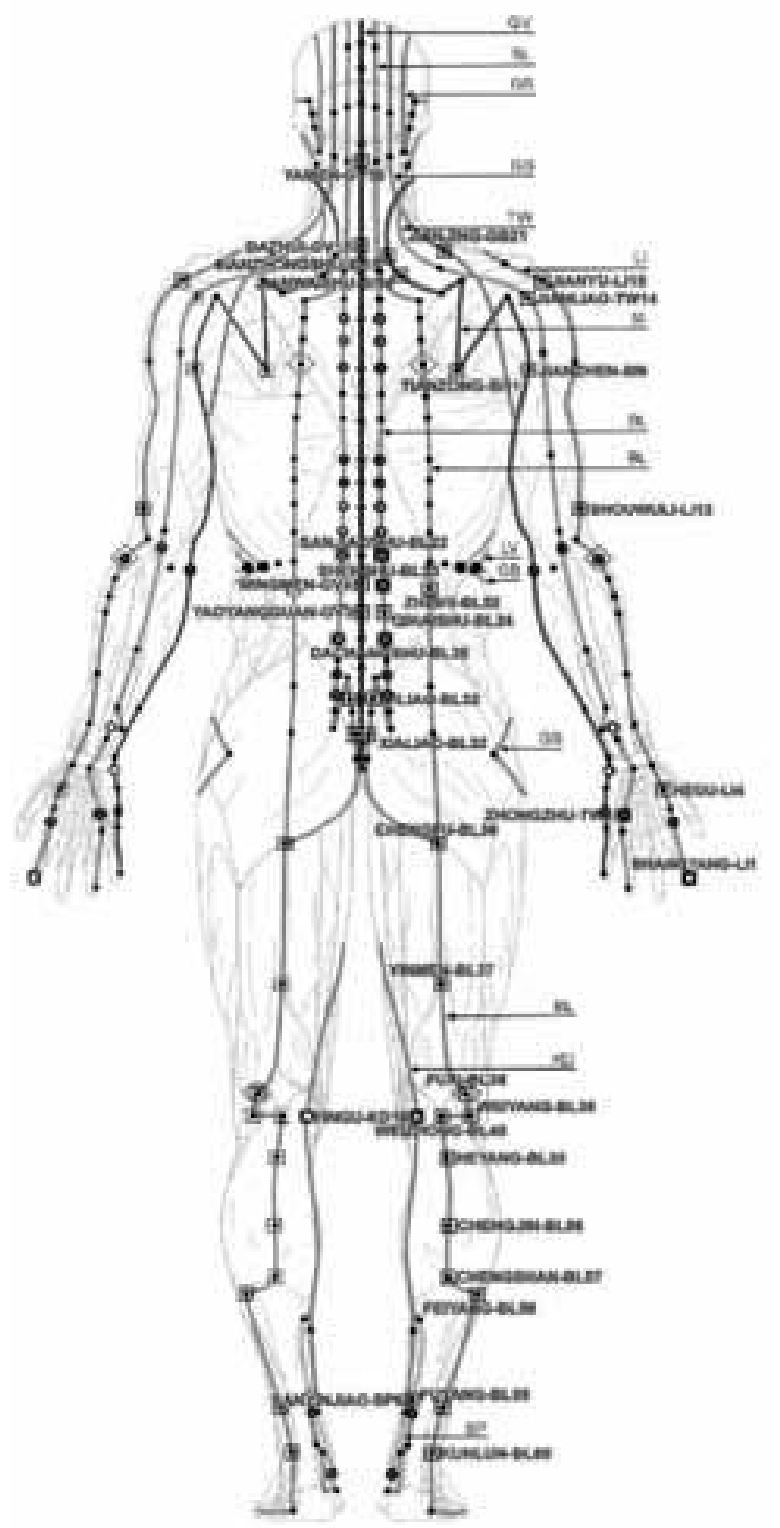

Fig. 1. Human body meridians and segmental points $(B L=$ bladder meridian $)$

The auricular point of the "sciatica" was used ipsi- or bilaterally, as well as the common auricular point Shenmen which was used bilaterally $(1,4,6)$.
Tolperisone hydrochloride 150-300 mg daily was added in the patients with painful spasm of the paravertebral muscles as the latter disturbs local blood circulation and oxygen supply, thus intensifying pain (9).

Pain was self-assessed by the patients using a visual analogue scale (VAS) modified by McGill $(5,8)$, ranging from 0 points (no pain at all) to 20 points (extremely severe pain). The test of Schober was also applied: ipsi- and contralateral flexion, measuring the distance from the fingers to the floor.

\section{RESULTS}

Based on the analysis of the clinical course, the VAS pain assessment, and the Schober test, followed up to 20 days after the initiation of treatment, we found alleviation of pain with 3 points, improvement of the vertebral syndrome, and reduction of the distance measured by about $23 \mathrm{~cm}$ after an average of 7 days in patients treated with acupuncture and muscle relaxants (tolperisone hydrochloride). No gastrointestinal adverse reactions were observed.

\section{DISCUSSION}

Our results support the opinion that early combined treatment (up to 4 weeks from the onset of symptoms) could lead to a decrease of the painful spasm of the paravertebral muscles, thus increasing mobility, improving quality of life and working capacity. It should be underlined that no sedative effect was observed. Local circulation and oxygen supply were improved. Acupuncture also has an analgesic effect through its typical neurochemical mechanisms of action, including enkephalin and endorphin opioid systems, as well as non-opioid neuropeptides of the hypothalamicpituitary system.

\section{CONCLUSION}

The analysis of our findings demonstrates the therapeutic effectiveness of combined treatment with acupuncture of BAP in patients with lumbar disc disease: quick improvement of pain and muscle spasticity, lack of gastrointestinal adverse effects, and therefore recovery of the impaired working capacity.

\section{REFERENCES}

1. È ëèåâ, Å., Âúëê̂̂ âà, Ò. Àêóï ói êòóðà đì đè

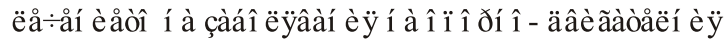
ài àđàò â ëói áî -ñàeđàëí àòà î áëàñò è òàçî́åäđåí èòå ñòààe. Àêói óí êò óðà, 2004, 1, 3-19.

2. Êî ñòàäè í î â, Ä. Áî ëêè â ãúđáà è êđúñòà. Ñ., 2000, 34-45.

3. İ åòđî â, Ï . İ î ÿñí î - äènêê âà áî ëåñò. Ñ., 1980, 23-35.

4. Chen Jing, A. Anatomical atlas of Chinese acupuncture points. 1982, 105, 165, 239. 
5. Cox, J. Low back pain. Baltimore, 1990.

6. Huskisson, E. Visual analogue scales. In: Melzack, R., ed,. Pain measurement and assessment. NY Raven Press, 1983, 33-37.

7. Kittang, G., Melvaer, T., Baerhaim, A. Acupuncture contra antiphlogistics in acute lumbago. South Med J, 2001, 94, 5, 486-492.
8. Melzack, R. The McGill pain. Questionnaire: major properties and scoring methods. Pain, 1974, 1, 277-299.

9. Pratzel, H., Alken, R., Ramm, S. Efficacy and tolerance of repeated oral doses of tolperisone hydrochloride in the treatment of painful reflex muscle spasm. Pain, 1996, 67, 417-425. 